\title{
Uterine fibroids embolization in a tertiary hospital: our initial experience
}

\section{Rooplekha Chouhan, Bharti Sahu*, Pooja Verma, Sapna Chouhan}

Department of Obstetrics \& Gynaecology, N.S.C.B. Medical College, R.D. University, Jabalpur M.P., India

Received: 20 April 2015

Accepted: 09 May 2015

\section{*Correspondence:}

Dr. Bharti Sahu,

E-mail: arvindsahu15@yahoo.com

Copyright: $\odot$ the author(s), publisher and licensee Medip Academy. This is an open-access article distributed under the terms of the Creative Commons Attribution Non-Commercial License, which permits unrestricted non-commercial use, distribution, and reproduction in any medium, provided the original work is properly cited.

\section{ABSTRACT}

Background: Uterine Fibroid Embolization (UFE) is a new modality which has appeared in the horizon for nonsurgical management of many conditions including fibroids. Moderate to severe anemia with fibroids is one of the reasons for delay in definitive treatment. Need for blood transfusion and its consequent risk of adverse reactions and diseases became a necessity to consider alternative treatment. Objective: To evaluate the efficacy and safety of UFE as an alternative to major surgery.

Methods: Seventeen women with symptomatic uterine fibroids who declined surgery or were at poor risk for surgery were treated by Uterine Artery Embolization (UAE). The uterine arteries were catheterised and embolized with polyvinyl alcohol particles. The patients were followed up at regular interval clinically and with transabdominal ultrasonography.

Results: UAE performed on all 17 patients had no major complications. Clinical follow-up showed a significant reduction in symptoms within six months of the procedure, with $79 \%$ improvement in menorrhagia and $86 \%$ improvement in pain. Follow-up imaging showed reduction in fibroid sizes ranging from $9-60 \%$. The mean procedural time was 150 minutes. The mean hospital stay was 5 days (range, 3 to 10 ).

Conclusions: Mid-term results of UAE for the treatment of symptomatic fibroids in our hospital indicate this to be a safe and effective therapeutic option.

Keywords: Fibroids, Embolization, Uterine artery, Minimal invasive

\section{INTRODUCTION}

Fibroids are the most common uterine tumours with about $50 \%$ prevalence at $35-45$ years of age. ${ }^{1}$ Out of all fibroids, at least $50 \%$ are estimated to be asymptomatic $^{2}$ and are more often than not left untreated. In symptomatic cases, however, fibroids can cause excessive menstrual bleeding, varying degrees of pain and, if large enough, significant pressure symptoms. In some cases they may even contribute to infertility by hampering implantation. ${ }^{3}$ A number of treatment options have been used over time, including surgery, pharmaceutical management, endometrial ablation and Uterine Fibroid Embolization (UFE). Though hysterectomy still remains the definitive treatment for fibroids, it carries with it a significant morbidity and mortality. Studies have shown abdominal hysterectomies to be associated with a significant morbidity in $3 \%$ of cases and minor morbidity in approximately $14 \%$ of cases. ${ }^{4}$ Various studies also show comparable results of abdominal myomectomies with UFE and indeed even suggest that UFE is safer with shorter recovery time. ${ }^{5,6}$ There are studies that show that patients can conceive and have successful pregnancy outcomes after UFE. ${ }^{7}$ UFE has hence gained considerable acceptance as an alternative treatment for uterine fibroids. Treatment of symptomatic fibroids by embolization of the uterine arteries was first reported by Ravina et al. in $1995{ }^{8}$ 
The purpose of this study was to try and establish the results of the few cases that we have performed at our institute.

\section{METHODS}

Seventeen patients of symptomatic fibroids, having declined, or deemed medically unfit for surgery fitting into our inclusion criteria were selected. Their symptoms assessed were of sufficient severity to be offered surgical management.

The inclusion criteria included healthy pre-menopausal women between 33 and 53 years of age not desirous of pregnancy, with large uteri attributed to fibroids, and with at least 1 of the following symptoms: anaemia, menorrhagia, dysmenorrhoea or pressure symptoms. Underlying gynaecological malignancy had to be excluded. The exclusion criteria included hypersensitivity to contrast angiography, undiagnosed vaginal bleeding, patients on anticoagulants or having clotting disorders, and immunocompromised patients, and patients not willing for the procedure.

Current and previous medical therapy for fibroids was recorded. An ultrasound of the pelvis was also performed and the uterine volume and the largest diameter of the dominant fibroid was obtained. Pre-procedural blood tests included full blood count, coagulation profile and creatinine and electrolyte levels.

The patients were admitted and were required to fast for 6 hours before the procedure. Intra-procedural sedation and analgesia was administered by midazolam hydrochloride. The right femoral arterial approach was utilised; a flush aortogram was first performed with the catheter tip positioned at the level of the renal arteries to identify the uterine arteries and any collateral supply from the ovarian arteries. After catheterisation of the internal iliac arteries with 4 to $5 \mathrm{~F}$ visceral catheters (Cobra) both uterine arteries were embolizred with polyvinyl alcohol (PVA) particles of 355 to 500 microns.

A repeat flush arteriogram was performed to confirm the occlusion of the feeding vessel. After embolization, all patients were given analgesics and an anti-emetic agent, ondansetron hydrochloride'. The length of hospital stay and occurrence of any complication was noted.

After discharge from the hospital, the patients were reviewed and pelvic sonography performed at 24 weeks. The severity of the presenting symptoms was reassessed. In addition, the patient was asked to rate her satisfaction level on a 5-point scale of very satisfied/moderately satisfied/no opinion/moderately dissatisfied/very dissatisfied.

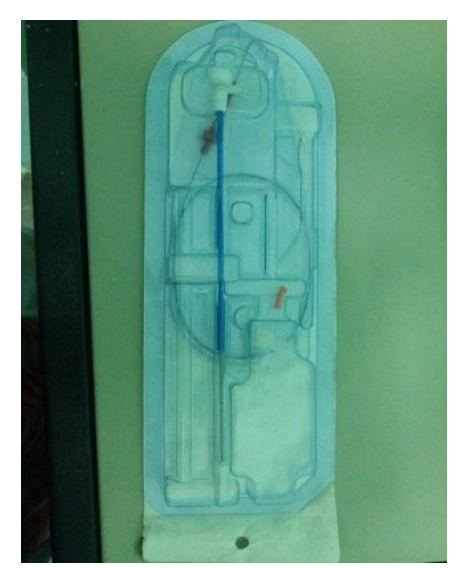

Figure 1: Angiosheath.

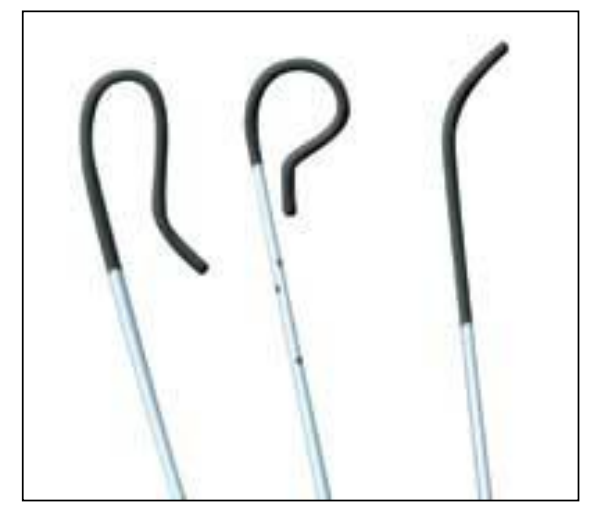

Figure 2: Cobra catheter.

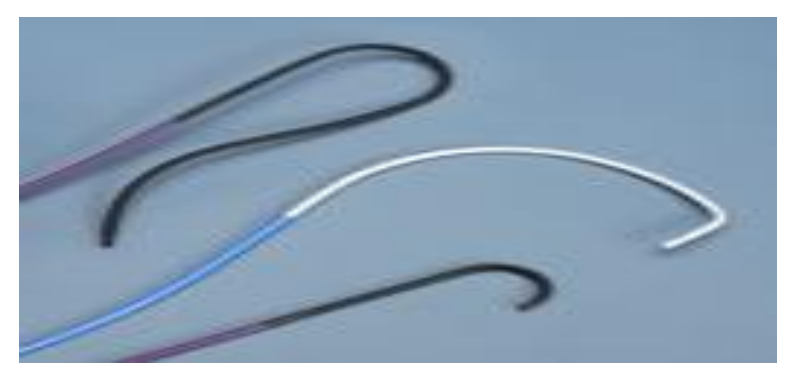

Figure 3: Robertson uterine catheter.

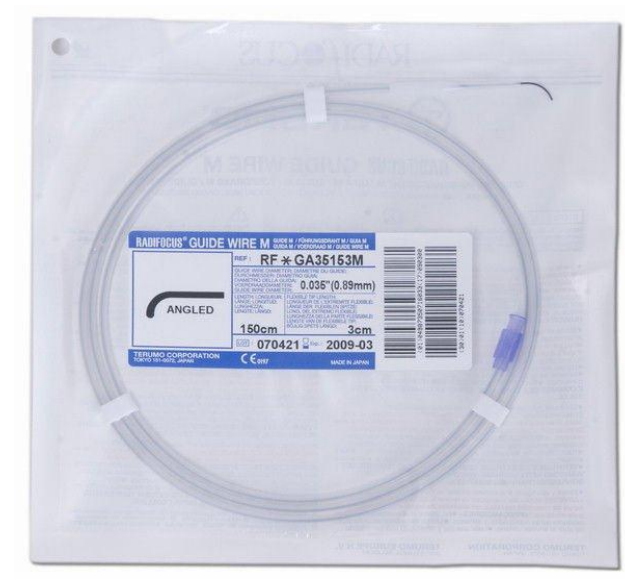

Figure 4: Terumo guide wire. 


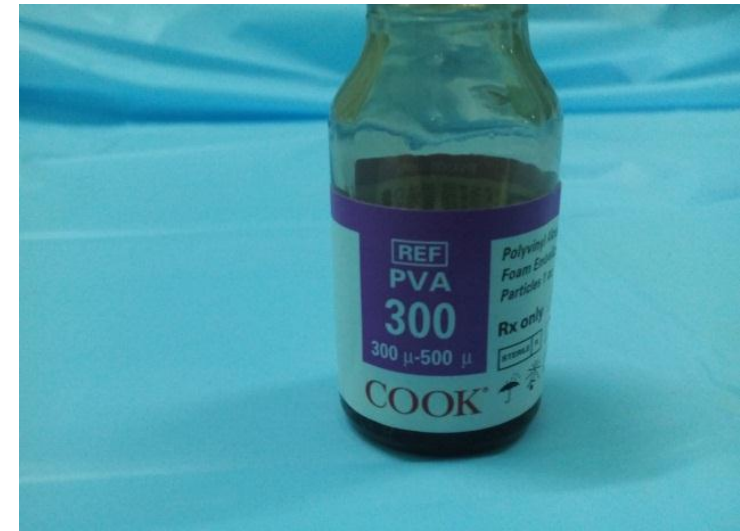

Figure 5: Poly vinyl alcohol particles.

\section{RESULTS}

Out of seventeen women aged between 33 and 53 years (mean, 43) menorrhagia was present in 9 women, dysmenorrhoea in 10 women, pressure symptoms in 11 women and anaemia in 16 women (Figure 6). The mean diameter of the largest fibroid was $6.4 \mathrm{~cm}$ (multiple small 1 to $7 \mathrm{~cm}$ ). The mean haemoglobin was $6.9 \mathrm{mg} / \mathrm{dl}$. UAE was successfully performed on all patients. Sixteen patients had both uterine arteries embolized; 1 patient had only the right uterine artery embolized on account of hypoplasia of the left uterine artery. The mean procedure time was $150 \mathrm{~min}$ (range, 60 to 270). There were no complications associated with the use of contrast mediums or catheters.

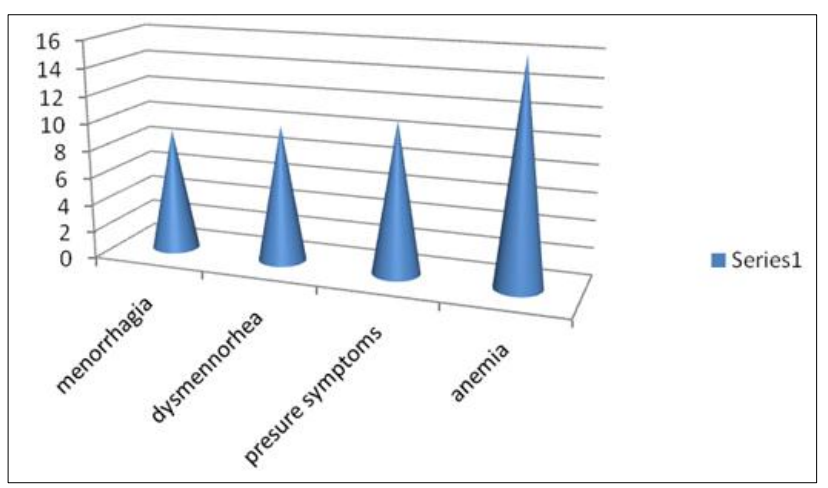

Figure 6: Presenting symptoms.

Post-procedural pain was well-controlled in 14 women. Three women had severe post-procedural pain.

The pain improved a few days later with continued analgesia. Fever was encountered in 8 women (2 of whom also had severe pain) that resolved with medical therapy. Six patients had annoying vomiting for 3-4 days which was controlled by ondansetron. 7 patients had discharge per vaginum and one of them reported of passage of fleshy mass (submucous fibroid polyp) (Figure 7). The mean hospital stay was 5 days (range, 3 to 10).

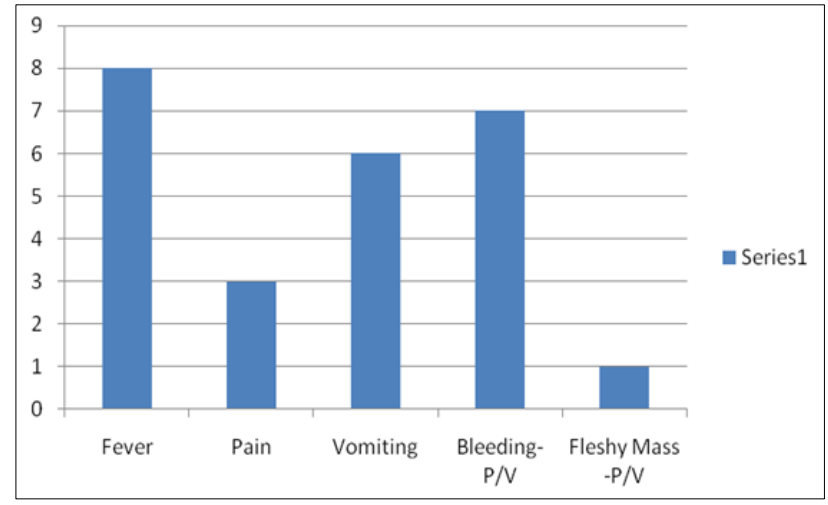

Figure 7: Post-procedural symptoms.

All patients reported improvement in the presenting symptoms. The mean decrease in diameter of the dominant fibroid at 6 months was $1.5 \mathrm{~cm}$ (range, 2.2 to 5.3).

Overall, 9 patients were very satisfied, 3 were moderately satisfied and 2 did not express an opinion on the results of the procedure and 3 lost follow up.

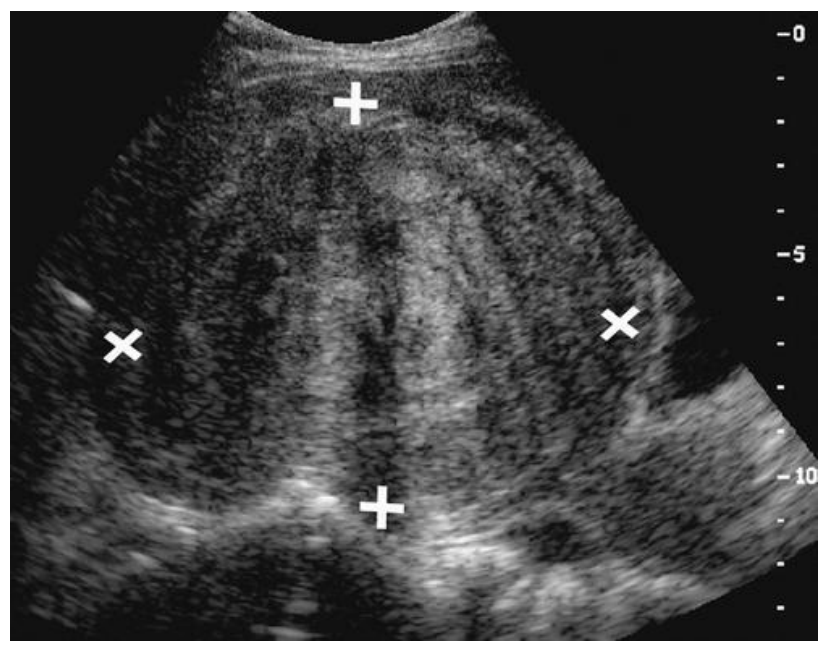

Figure 8: USG image pretreatment.

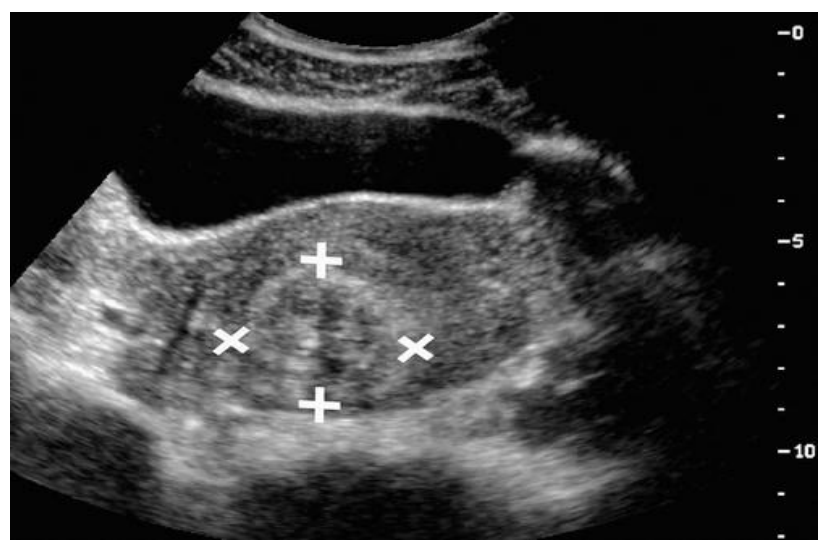

Figure 9: USG image post-treatment. 


\section{DISCUSSION}

Since the first report of UAE as the primary treatment for uterine fibroids, the procedure has grown rapidly in popularity with subsequent reports showing encouraging results. Like all procedures, however, it has its own set of complications. Major complications include fibroid passage, pelvic infections, uterine necrosis, fibroid regrowth, ovarian failure, deep venous thrombosis and rarely even death. Minor complications include haematoma formation, urinary retention/urinary tract infection, pain, and injury to neurovascular bundle at the site of the puncture.

A recent review of the literature showed that the mortality rates of UAE and hysterectomy were low, at $0.01 \%$ for both. ${ }^{10}$ The operative injury of surgery (myomectomy and hysterectomy both at 1\%) was, however, higher than that for UAE $(0 \%)$.

UAE recorded $90 \%$ improvement in menorrhagia while myomectomy recorded $81 \%$ improvement.

There are few studies like of Bruce McLucas et al. and of Pron $G$ et al. available that show similar fertility rates after UFE in comparison to myomectomy ${ }^{11}$ although with higher risks for pre-term delivery and malpresentation. ${ }^{12}$ Pedunculated subserosal fibroids were previously thought to be a relative contraindication to UFE due to the potential risk of stalk necrosis and detachment of fibroid leading to peritonitis. Studies, however, currently show that pedunculated fibroids with stalk diametres more than $2 \mathrm{~cm}$ are not associated with increased complications. ${ }^{13}$

Limitations of our study include its single-centre nature as well as a small sample size due to which results cannot be generalized.

\section{CONCLUSIONS}

The results of minimally invasive UAE for the treatment of symptomatic fibroids in our hospital indicate this to be as safe and effective therapeutic option. A longer period of follow-up with a greater number of patients will be needed to confirm that $\mathrm{UAE}$ is a viable option, acceptable to both patients and clinicians.

\section{Funding: No funding sources}

Conflict of interest: None declared

Ethical approval: The study was approved by the institutional ethics committee

\section{REFERENCES}

1. Van den Bosch $\mathrm{T}$, Coleman A, Morina M, Timmerman D, Amant F. Screening for uterine tumours. Best Pract Res Clin Obstet Gynaecol. 2012;26:257-66.

2. Divakar H. Asymptomatic uterine fibroids. Best Pract Res Clin Obstet Gynaecol. 2008;22:643-54.

3. Uba FA. Uterine fibroids: which treatment? Niger Med J. 2011;52:149.

4. Lumsden MA, Twaddle S, Hawthorn R, Traynor I, Gilmore D, Davis J, et al. A randomised comparison and economic evaluation of laparoscopic-assisted hysterectomy and abdominal hysterectomy. BJOG. 2000;107:1386-91.

5. Razavi MK, Hwang G, Jahed A, Modanlou S, Chen B. Abdominal myomectomy versus uterine fibroid embolization in the treatment of symptomatic uterine leiomyomas. AJR Am J Roentgenol. 2003;180:15715 .

6. Narayan A, Lee AS, Kuo GP, Powe N, Kim HS. Uterine artery embolization versus abdominal myomectomy: a long-term clinical outcome comparison. J Vasc Interv Radiol. 2010;21:1011-7.

7. Walker WJ, McDowell SJ. Pregnancy after uterine artery embolization for leiomyomata: a series of 56 completed pregnancies. Am J Obstet Gynecol. 2006;195:1266-71.

8. Ravina JH, Herbreteau D, Ciraru-Vigneron N, Bouret JM, Houdart E, Aymard A, et al. Arterial embolisation to treat uterine myomata. Lancet. 1995;346:671-2.

9. Kitamura Y, Ascher SM, Cooper C, Allison SJ, Jha RC, Flick PA, et al. Imaging manifestations of complications associated with uterine artery embolization. Radiographics. 2005;25(Suppl 1):S119-32.

10. Broder MS, Landow WJ, Goodwin SC, Brook RH, Sherbourne CD, Harris K. An agenda for research into uterine artery embolization: results of an expert panel conference. J Vasc Interv Radiol. 2000;11:50915.

11. McLucas B, Goodwin S, Adler L, Rappaport A, Reed R, Perrella R. Pregnancy following uterine fibroid embolization. Int $\mathrm{J}$ Gynecol Obstet. 2001;74:1-7.

12. Goldberg J, Pereira L, Berghella V, Diamond J, Daraï E, Seinera P, et al. Pregnancy outcomes after treatment for fibromyomata: uterine artery embolization versus laparoscopic myomectomy. Am J Obstet Gynecol. 2004;191:18-21.

13. Katsumori T, Akazawa K, Mihara T. Uterine artery embolization for pedunculated subserosal fibroid, AJR Am J Roentgenol. 2005;184;399-402.

DOI: $10.18203 / 2320-1770 . i j r \operatorname{cog} 20150100$

Cite this article as: Chouhan R, Sahu B, Verma P, Chouhan S. Uterine fibroids embolization in a tertiary hospital: our initial experience. Int J Reprod Contracept Obstet Gynecol 2015;4:824-7. 